\title{
ResearchOnline@JCU
}

This is the author-created version of the following work:

Lowrie, Daniel, Ray, Robin, Plummer, David, and Yau, Matthew (2019) Examining the transitions between living and dying roles at end-of-life. Death Studies, 43 (10) pp. 601-610.

Access to this file is available from: https://researchonline.jcu.edu.au/56782/

Published Version: (C) 2018 Taylor \& Francis. Accepted Version may be made open access in an Institutional Repository without embargo.

Please refer to the original source for the final version of this work: 


\section{Examining the transitions between living and dying roles at end-of-life}

Daniel Lowrie $\quad$ BHSc (OT), MSc

Lecturer and PhD Candidate. College of Healthcare Sciences, James Cook University, Townsville, Australia.

Robin A. Ray $\quad$ BEd, MHSc, PhD

Associate Dean, Research Education. College of Medicine and Dentistry, Anton Breinl Research Centre for Health Systems Strengthening. James Cook University, Townsville, Australia.

David Plummer $\quad$ AM, MB, BS, PhD

Adjunct Professor. College of Medicine and Dentistry, James Cook University, Townsville, Australia.

Matthew Yau $\quad$ BAppSc, MCom, MSc (Hons), PhD, OTR, CST

Head and Professor. Department of Rehabilitation and Social Sciences, Tung Wah College, Kowloon, Hong Kong.

First published (online) $-4^{\text {th }}$ October 2018. Published in hard copy of journal in 2019.

Death Studies, 43(10), 601-610 1-10. DOI: 10.1080/07481187.2018.1504836 


\begin{abstract}
Improvements in the diagnosis and disclosure of dying mean that nowadays dying people typically live with an awareness of their status for longer than they have previously. However, little is known regarding how transitions between living and dying roles occur during this time. In this grounded theory study, we investigated role transitions at end-of-life. We found that dying people periodically foreground and background living and dying selfhoods, focus on living day-by-day and goal-by-goal and reframe dying roles with an orientation to living. We argue that with better understanding of role transitions at end-of-life more compassionate and responsive care becomes possible.
\end{abstract}

\title{
Key words
}

Dying roles; living and dying selfhoods; role change; palliative care 


\section{Examining the Transitions between Living and Dying Roles at End-of-Life}

It has been over half a century since Glaser and Strauss (1965) published their seminal work titled Awareness of Dying. Their research highlighted a tendency for the health professionals and loved ones of dying people to hide their dying status from them for large portions of the dying journey, with open awareness of dying occurring only when death was very near. Much has changed in relation to disclosure and awareness of dying since that time. Improvements in the diagnosis of dying, coupled with a tendency among doctors towards greater openness and transparency in the disclosure of dying, mean that many dying people live with awareness of their status for long periods of time (Field, 1996; Field \& Copp, 1999). This knowledge has been identified as bringing with it several benefits such as the ability to better plan for and control various aspects of the dying process (Field \& Copp, 1999; Howe, 2016; Seale, Addington-Hall, \& McCarthy, 1997) as well as greater peace with dying (Lokker, Zuylen, Veerbeek, Rijt, \& Heide, 2012). Changes to clinical practice have also been accompanied by a broader societal shift in relation to awareness of dying, resulting in a gradual rekindling of death and dying in films, plays, novels, and general parlance (Doka, 2003; Walter, 1994; Walters, 2004). More recently, successful efforts to further normalize discussion regarding death and dying at a community level have been noted in relation to initiatives such as the Dying Matters Coalition (Nyatanga, 2013) and Death Café movement (Baldwin, 2017; Miles \& Corr, 2017).

Despite these developments in the recognition and management of dying, little is known of what way, if any, they have influenced the enactment and experience of contemporary dying roles. The need for a better definition, identification, and enactment of the dying role as a means of improving end-of-life care was discussed over 40 years ago by Noyes and Clancy (1977). In particular, Noyes and Clancy highlighted a lack of clear distinction between sick roles and dying roles, suggesting that role confusion resulting from 
extension of the sick role compromised the completion of key end-of-life tasks such as completion of wills and transfer of authority in household and business affairs. Given the important function that dying roles can play, there has been surprisingly little published research specifically focusing on these roles over recent decades. Two notable exceptions to this can be found in an application of role theory to palliative care by Emanuel, Bennett, and Richardson (2007) and Parker-Oliver (2000).

Emanuel et al. (2007) describe the dying role as having practical, relational, and personal features. They assert that the practical facets of the dying role include tasks such as construction of wills, completion of advance directives, and funeral planning. Relational dimensions of the dying role entail tasks including symbolic handover of role responsibilities, permission to the living to 'move on', and efforts by the dying person to finalize his or her life story and forge legacy. Finally, personal features of the dying role incorporate revisiting (and/or acting on) existential beliefs regarding end-of-life, adjusting to loss and change, and seeking closure of (and, at times, growth in) relationships (Emanuel et al., 2007). Although Emanuel et al. (2007) acknowledge that uncertainty exists in the way in which dying people transition between living roles and dying roles, their paper focuses predominantly on the form and function of the dying role rather than the way in which it unfolds over time.

Insights into the process of role change at end-of-life are, however, offered in ParkerOliver's (2000) dramaturgical analysis of dying within the context of hospice care. ParkerOliver (2000) emphasize the inadequacy of the sick role in the drama of the dying and highlight the value of the hospice community in acting as a catalyst for the effective transition to the dying role. She suggests that successful role transitions are achieved when the hospice team members act as co-directors in the drama of dying (along with the dying person and close relatives), thus preventing role confusion among the various actors for whom dying roles will often be new. Her analysis focuses on three key scenes, namely the 
introduction of the dying role, the fulfilment of the dying role, and the deathbed scene.

Details are provided in relation to each of these scenes concerning the potential function of the hospice community in guiding dying people and their loved ones in a manner that supports them in achieving role clarity and extracting meaning and fulfilment from the time remaining. While the ideas presented by Parker-Oliver (2000) are valuable, they focus heavily on the function of hospice services in shaping role transitions and role relations. Her analysis is thus limited in scope to the elements of the dying journey in which hospice staff play a prominent role. Although these scenes are important, they do not necessarily reflect the broader drama of dying, most of which is played out beyond the reach and influence of hospice services.

The research presented in this paper aims to build on the evidence base described above by offering an examination of the relationship between living and dying roles within the context of the contemporary drama of dying. Particular attention is paid to the way in which dying people and those around them negotiate role transitions within what nowadays is often a lengthy period of time between diagnosis of dying and the actual event of death. Priority has also been given to the perspectives and experiences of dying people and their family and friends. It is hoped that, in doing so, a more comprehensive picture of the dying experience will be achieved, thus positively influencing health care practice.

\section{Methodology}

The findings presented here form part of a broader Australian-based study examining the process of role change at end-of-life. The overarching research adopted a qualitative design utilising a constructivist grounded theory approach to guide the process of data collection and analysis. The findings specifically described in this paper relate to one of the categories arrived at through this process, 'oscillating between living and dying selfhoods'. 
Grounded theory is a research methodology that supports the development of a robust explanatory framework regarding a social process, action or interaction founded on the views of participants. Grounded theory studies involve a progressive process of in-depth analysis of individual cases from which researchers extrapolate more general explanations concerning the process being studied (Bryant \& Charmaz, 2010). It is through this ongoing and systematic process of categorization and comparison of research data that the development of theory occurs. In constructivist grounded theory studies, key concepts and subsequent theory are derived from, and are grounded in, research data, but the role of the researchers in interpreting data and constructing theory are acknowledged (Charmaz, 2014).

\section{Sampling and Recruitment}

In order to better understand the relational nature of dying roles, this research examined the perspectives of dying people as well as the perspectives of their family members and/or caregivers. Participants in this research project were recruited purposively through the adoption of a theoretical sampling approach to promote maximum variation within the sample (Creswell, 2013; Morse, 2010). Theoretical sampling began quite broadly and became increasingly focused and circumscribed as the study progressed, thereby enabling the development and refinement of emergent theory (Dey, 2010).

Potential participants were made aware of this study through an information flyer and participant information sheet. Copies of these were displayed in the regional Palliative Care Centre and were provided to members of the local Palliative Care Outreach Team for distribution to individuals who might be interested in participating in the study. Participants were deemed eligible for inclusion in this study if they had been diagnosed as having a life expectancy of six months or less, or were a family member and/or caregiver of an individual with a life expectancy of six months or less. Potential participants were considered ineligible for the study if they were younger than 18 years of age, had rapidly deteriorating conditions, 
were identified as being within the last 48 hours of life, or had conditions or symptoms that negated their ability to participate meaningfully in an interview.

The sample size for the research project was based on the principle of data saturation. Therefore, recruitment continued until no new variant cases emerged and no new themes were identified within the interview data (Glaser \& Strauss, 1967). A total of 21 participants were interviewed in this study - 13 dying people (identified in this paper as P1 to P13) and 8 family caregivers (identified as $\mathrm{C} 1$ to $\mathrm{C} 8$ ). Five dying person-caregiver dyads (totalling 10 participants) were present among the participant sample. Twelve participants were women (5 dying people and 7 carers) and 9 were men ( 8 dying people and 1 carer). Participants' ages ranged from 30 to 87 and averaged 69 for dying people and 57 for carers. Thirteen participants identified as White Australian, 1 as Aboriginal Australian, 5 as White British, and 2 as White New Zealander. All participants were living in Australia. Eleven participants described themselves as working class and 10 as middle class. Among the 13 dying persons, 10 had cancer diagnoses, 1 had motor neurone disease, 1 had chronic obstructive pulmonary disorder, and 1 indicated having multiple diagnoses.

\section{Data Collection and Analysis}

Data were collected with semi-structured interviews undertaken by the first author. Two interviews were conducted with the dying person and caregiver both present; the remainder were undertaken individually. An interview guide was used as a flexible tool for structuring interviews and as a prompting device. The research team (all four study authors) developed this interview guide based on their professional and research experience as well as on a broad ranging review of the literature. The interview guide was modified by the research team following preliminary data analysis after each interview in order to enable the continued refinement of emergent theory (Charmaz, 2014). 
Interviews were conducted at a time and location agreed upon by the participant and the first author, most often in participants' homes. Interviews ranged in length from 30 minutes to 177 minutes, with the average interview length being 88 minutes. All interviews were digitally recorded and transcribed verbatim to enable data analysis. NVivo Pro software $^{\odot}$ (version 11) was used to assist in organising data during the analysis process.

Data were analysed through the use of a grounded theory framework (Glaser \& Strauss, 1965) with modifications recommended by Layder (1993) to accommodate observational evidence, documents, and artefacts and also by Charmaz (2014) to reflect a constructivist and interpretive stance. Theory was developed and refined through the iterative processes of coding, analysis, and comparison. Theory generation was further guided through the blended application of narrative inquiry and dramaturgical analytical lenses. The lens of narrative inquiry assisted in facilitating an understanding of the reciprocal relationship between each participant and his or her social context by focusing on experiences, milestone events, key characters, and chronology (Creswell, 2013; Thomas, 2012). Dramaturgy (which draws on the metaphor of theatre as a framework examining human interactions) served as an analytical device in examining role enactment and role relations at end-of-life (Goffman, 1959). Specifically, it enabled analysis of the various scripts, props, costumes, gestures and so on employed by the various actors in co-constructing and maintaining the drama of dying through their interactions (Goffman, 1959).

Substantive coding of the research data began with open (initial) coding. The first author undertook a process of line-by-line coding of data, in which 'key incidents' from the participants' narratives were compared to each other and to the emerging concept. This process of line-by-line coding helped in ensuring that no important categories were omitted and that the identified categories were saturated with rich and relevant data (Glaser \& Holton, 2004). Initial codes were discussed among the whole research team and revised, based on 
feedback and discussion. Focused coding was then conducted in order to refine the emerging conceptual framework. This process involved the targeted collection and analysis of data, through theoretical sampling and constant comparison, to refine the logic and boundaries of the theory (Holton, 2010).

Theoretical notes ('memos') were recorded by the first author throughout the data collection and analysis phases. These memos were used in mapping the emergence of codes and categories and, in turn, the development of theory. Memos were discussed with the research team along with the open and selective coding processes to guide analysis and foster a robust and transparent reasoning process (Saldana, 2013). The first author also maintained a research diary in order to make notes on thoughts, feelings, and observations relating to interviews for later discussion and analysis. Both the diary entries and theoretical memos assisted in identifying, examining and appropriately managing researcher perspectives and biases, thus promoting reflexivity (Snowden, 2015) and provided an audit trail of the analytic processes. An example of the progressive development of codes, memos, and theory in this research is outlined as a conceptual map in Appendix. 1. This particular conceptual map relates to the development of one theme from this study ('foregrounding and backgrounding of living and dying selfhoods').

\section{Ethical Considerations}

The study received ethical approval through the local Health Service Human Research Ethics Committee (approval number HREC/14/QTHS/196) and University Human Research Ethics Committee (approval number H6101). Participants were informed in writing that they were not obliged to participate in the study and that they had the right to withdraw at any stage without consequence (prior to the final processing of their data). Given the sensitivity of the research topic, consent was revisited after the completion of each interview to ensure that participants remained happy for their narrative to form part of the study (Byrne, 2001). 
Participant confidentiality was maintained by the removal of all identifying information at the point of transcription. Identifying information relating to people mentioned by participants in their interviews was also removed at this point.

\section{Findings}

Four interrelated themes were identified through the data analysis process. The first theme, 'existing in an elongated and ambiguous space' highlights the difficulties that dying people and their family and/or caregivers experienced in navigating the experience of living with a dying diagnosis. The remaining themes of 'foregrounding and backgrounding living and dying selfhoods'; 'living contingently'; and 'preserving hope through reframing dying roles' all discuss the way in which dying people and their caregivers respond to these difficulties.

\section{Existing in an Elongated and Ambiguous Dying Space}

Both the dying people and their family/caregivers in this study made frequent references to the existence of an elongated and ambiguous timeline between the diagnosis and the actual event of dying. Interestingly, almost all of the dying people interviewed reported to have far exceeded the prognoses suggested to them by their treating doctors. For example, P8 stated; "When I got diagnosed with the brain cancer, they said, 'oh, you'll probably only last about three months'. That was four years ago.” A number of participants even reported that it had been suggested to them that they might have set some sort of survival record.

“The palliative care doctor didn't think I'd survive anywhere near where I am now. My GP [General Practitioner], I said to her the other day, 'look, I think that I'm going

to make medical history.' And she said 'I think you already are making it."' (P2)

It would be unreasonable to suggest, based on this sample of dying people outliving their prognoses, that under-prognostication is routine, given the obvious fact that only people 
who were still alive were interviewed. The data does suggest, however, that it is not uncommon for dying people to remain alive far beyond the estimated prognoses indicated to them by medical professionals. Although, in many ways, living longer than expected might be regarded as positive, several participants highlighted the emotional burden associated with maintenance of a dying identity for long periods. As well as this emotional toil, the associated loss of prognostic clarity also brought with it a degree of difficulty and frustration for dying people and their caregivers who bemoaned the lack of control and inability to plan that accompanies an uncertain dying trajectory:

"Don't tell her she's got a month if you don't know it's going to be a month, because when the doctor told her you've got a month she expected to be gone in a month, and that was really hard when she wasn't... He was adamant. He said you're not going to be here at Christmas time, I'll guarantee you that... So I would recommend don't tell the person unless you're 100 per cent [voice breaks] certain that they've got X amount of time, because that really did her head in, it really did. In a way it did mine too because I was - I couldn't plan anything. I've got a boy whose birthday's before Christmas. [I thought] Oh, don't die on my boy's birthday, or close to there. It's going to do him in. Oh, is it going to happen at Christmas. Everybody's saying 'what are you going to be doing for Christmas?'... I didn't know what was going to be happening for Christmas because I didn't know if she was going to be here or not. So - don't tell people if you don't know." (C1)

"I guess from the planning point of view it would be really nice to know this is exactly... how much time you've got... I guess that's one of the frustrations, is just not knowing. It doesn't seem to matter where you get to, you never know how much time you've got left, you know?” (P10) 
In being confronted by the knowledge that they are in a dying state, compounded by the lack of clarity as to when they would actually die, participants found themselves existing in highly contingent states of being. Given the emotional burden associated with the dying role, most seemed to resist identifying themselves as dying persons by focusing on themselves as living beings for the majority of the time. Nevertheless, the reality that death was nearing remained ever present. Participants managed this duality through the processes of periodically foregrounding and backgrounding their living and dying selfhoods, living contingently, and reframing dying roles as living roles.

\section{Foregrounding and Backgrounding Living and Dying Selfhoods}

The dying people in this study did not describe linear and/or fixed status shifts from living to dying; instead, they seemed to periodically foreground and background their living and dying selfhoods at different times. For example, one participant described the way in which he foregrounded his living self when at home but backgrounded this when in hospital:

"I like to live two lives. I like to live the life that I've got at home and all of the happiness and everything around with my grandkids, and all of the things that I can do with them now, even with the limitations that I have... I like to live that life and then, if I have to go into the hospital...I live that life on that day or in that week. Then when

I leave there, that's it, I'm back to my other life, and it works... It just keeps me from falling into a depressive state or whatever.” (P5)

The decisions as to which facet of self to project and role to play lie ultimately with the dying persons themselves, but this is heavily influenced by a variety of events and contextual factors, particularly if these factors are deemed to be important to them. For example, many participants recounted stories regarding the point at which their treating doctors first indicated that their condition was incurable and subsequently referred them to palliative care. During this time, the dying self was foregrounded as the dying person 
attempted to adjust to his or her changed status and deal with the immediate practical and relational implications that accompanied it.

"So they were big times of talking through a lot of things, talking through end of life things, just [my wife] and myself. Just thinking, well okay, if we have to face that this is what we're facing, then we have to do it together. We have to do all this - and making preparations, doing things that we know will be helpful later.” (P9)

This focus on dying served a particular purpose at the time. In subsequent (and nonmedical) social encounters, however, these same individuals would often block attempts from members of their social network to draw them towards a projection of themselves as dying: “... generally, I find people come out wanting to know the ins and outs of everything, how you're feeling today, where is it and all this sort of stuff. You get fed up with that. I'm not going to talk about that anymore.” (P9)

All of the dying people interviewed seemed to resist the dying identity by foregrounding their living selfhood for the majority of the time. However, periodically they would instead endeavour to foreground their dying self as they engaged in tasks such as arranging their affairs or as they attempted to speak with their loved ones regarding their thoughts and feelings about dying. Curiously, many participants described these attempts at foregrounding their dying selfhood with close friends and families as being met, at times, with resistance, resulting in the dying role remaining out of bounds.

\section{Living Contingently}

By far, the most common phrase in the narratives of dying people and their caregivers related to the necessity of 'living day-by-day'. When using this phrase, participants sometimes seemed to be describing efforts aimed at making the most of their remaining time. Participant P2 offered an example of this; "So yeah, so that's where I'm at, at the moment, just taking it a day at a time and making the most of every day." Participant P6 expressed 
similar sentiments highlighting the importance of being at home in living life to the fullest; "So I'm grateful to be in our own home and just, as I say, I take one day at a time. It's just make the most of everything and, you know."

There was also, however, a second meaning at play that centred on the ambiguity and uncertainty emanating from the lack of clarity as to when the final stages of dying might actually begin. This resulted in a highly contingent state of being for dying people and their caregivers who were faced with the impending reality that the dying person would die sometime soon although there was a lack of certainty as to when. For example, participant P8 described the loss of control that accompanied prognostic ambiguity; "So at the moment, I just wake up every morning, I'm always it's another day, you know, so I just think, well, just go with it. There's nothing I can do about it." In response to these situations of uncertainty, dying people and their caregivers attempted to regain a sense of agency through the foregrounding of role relations founded on a tentative cycle of day-by-day living. As such, they seemed to be ad-libbing much of life's final act, while they awaited the declaration that the closing scene had arrived.

"I think I've just put it out of my mind and I live my life day-by-day. As my wife says, 'you know, yeah, you're going to die but not today'. We've both sort of operated on that sort of level." (P5)

One way that dying people and their caregivers extended the sense of control over the dying process involved shifting their mindset from living day-by-day towards living on a goal-by-goal basis. Goal-by-goal living helped in ensuring that each scene in life's final act had a point of focus and purpose, thereby countering some of the uncertainty and mundanity of day-by-day living. Each milestone offered a source of hope that alleviated thoughts and feelings of simply waiting for death, thus allowing the dying person to nurture a stronger hold on his or her living selfhood: 
"I've got at the moment a little bucket list going, so I'm sort of trying to just get to do them... I've got [grandson], right here. [daughter] [40] next year, [granddaughter] is 16 next year... [Interviewer - You just keep ticking them off, do you?] "Yep. I think it keeps me going." (P8)

“Then of course, he probably would have told you [daughter]'s having a baby next year so we will be grandparents for the first time in April. So now that's become a really big focus for him; that I'm going to work hard to stay around for the baby's birth and all that sort of stuff. So yeah, it's about giving him some hope and some forward thinking when everything gets too tough." (C4)

\section{Preserving Hope by Reframing Dying Roles}

Dying people and those closest to them also lessened the emotional burden associated with the dying role by leveraging the conceptual overlap between living and dying. This overlap allowed key elements of the dying role to be enacted under the guise of a focus on living. This was particularly evident in situations such as special social gatherings that had been arranged for the dying person by their families. Generally, such events were highly regarded. For example, participant $\mathrm{C} 3$ recounted the story of a recent family holiday that had been organised by her children; "We went up to [small town] to the village up there, and had a wonderful time. The children came from [out of state] for the school holidays so we went up there for a couple of days." Similarly, participant P5 spoke at length about his feelings of excitement in relation to an upcoming getaway; "We've got a house booked over on the island, a beautiful home, and the whole family's going to be there."

It is worthy of note that, although everyone knew the intention of these events, there tended to be an unspoken requirement for all parties to adhere to a social script in which reference to or focus on dying remained off-limits. This led to encounters in which, although all parties knew of the dying individual's status, it was not discussed or even acknowledged. 
While, at face value, this state of affairs may seem contradictory, it served a purpose in allowing at least some relational and personal elements of the dying role to be enacted, without highlighting the dying status of the dying person:

"[P10] sort of said at his birthday party to everybody 'I'm not a man of many words... all I can say is see you next year for my birthday next year'. Anyway, [daughter] said to me later, 'Mum, do you really think he thinks that he may be alive next November?' I said, 'Darling, I don't know'. She said, 'Oh, surely he knows that'. I said, 'Well, I'm certainly not going to say it to him'... and also the people who are here, they want to have hope as much as he wanted to have hope. So we can't take that away from people but even she felt - I could tell that she knew. I mean, everyone knows." (C4)

In a similar fashion, following their dying diagnosis, some participants undertook activities that were focused on making the most of moments with their family. Again, by couching these activities in terms of living life to the fullest, the dying persons and those around them were able to enact some aspects of the dying role (such as forging memories) without the need to acknowledge dying per se. An important and influential taboo concerning the fear of destroying hope is at play in all of these circumstances. Maintenance of hope is regarded as a central tenet in the contemporary drama of dying and all actors are exposed to considerable social pressure not to do or say anything to undermine it. By accepting and enacting a position of shared pretence whereby the dying person's status is backgrounded all parties ensure that this taboo is not broken.

Although, for the most part, this shared pretence seemed to work well, it did, on some occasions, result in missed opportunities that a more overt acknowledgement of dying might have afforded. For example, participant P6 reflected on conversations that she had wanted to have with her immediate family who had visited from overseas but had not managed to 
because of a busy schedule focused on doing things together; "I think [voice breaks] there were things that probably needed to be said too, that didn't get talked about."

\section{Discussion}

Our research findings suggest that heightened awareness of dying in what is increasingly an elongated dying space can result in significant emotional burden for dying people and their caregivers. Taken collectively, the findings of our research offer insights into a number of ways in which dying people and those close to them might manage this emotional burden. As such, these findings have important implications both conceptually and clinically.

The tendency for dying people to periodically foreground and background their living and dying selfhoods points to the idea that the transition to a dying status is not a fixed or linear process for many individuals. In historical times, fixed status shifts may have served a necessary function because the time between recognition (or disclosure) of the dying status and the event of death tended to be brief (Aries, 1981; Kellehear, 2007). Hence, the dying role needed to be (and typically was) enacted in a relatively quick and ongoing manner. However, these fixed status shifts do not seem to be sustainable in the lengthier drama of contemporary dying, especially with respect to the personal and relational facets of the dying role. In response to this, dying people oscillate between living and dying roles with a tendency towards projection of their living selfhood for the majority of the time. The notion of dying as an oscillating state of being and the associated challenges that this can bring for dying people and their caregivers have been discussed previously in the literature (Breen, Aoun, O'Connor, Howting, \& Halkett, 2018; Kellehear, 2009). Our findings add to this picture by highlighting the possibility that the emotional burden associated with the contemporary dying role render these temporary transitions both commonplace and necessary in protecting the well-being of dying people as well as their family and /or caregivers. 
Our findings also suggest that, to some extent, heightened awareness of dying, without prognostic clarity, seems to compromise, rather than enhance, the sense of agency and control over one's life that disclosure of dying is intended to provide. Although disclosure of dying unquestionably enables timely enactment of the practical dimensions of the dying role, many of its relational and personal aspects are most suited to the closing scenes of life and there is often considerable uncertainty as to when this will commence. The rather tentative focus of dying people and their caregivers upon day-by-day and goal-by-goal living can be understood as a means of re-asserting a degree of control and clarity back into their lives.

The manner in which many participants in our research reframed dying roles in the context of living can also be seen as a mechanism for coping with prognostic uncertainty in an elongated dying space. This mindset reflects a contemporary extension of what Glaser and Strauss (1965, p. 64) termed "mutual pretence" (p. 64). Mutual pretence refers to an awareness context in which all parties know of a dying person's status but nobody openly acknowledges or discusses it. Mutual pretence seemed to serve a protective function for many of the participants in our research by ensuring that, despite being aware of their dying status, they did not have to refer to it for the majority of the time. Interestingly, by reframing the dying as having a focus on living, dying people and those close to them managed to enact many of the dying role's personal and relational elements, without overtly and/or prematurely foregrounding the dying selfhood.

A central theme concerning the preservation of hope is present in all of the findings presented in this paper. Discussions between doctors and dying people regarding prognostic record breaking, the foregrounding of the living selfhood (and living roles), and the emphasis that dying people place on goal-by-goal living might all be understood in this light. Furthermore, the tendency for dying people and those close to them to avoid overt 
acknowledgement of the dying status (in most situations) is reflective of the presence of a deep taboo regarding the destruction of hope.

Recent research has indicated that dying people place considerable importance upon the maintenance of hope, regardless of their disease stage (Broadhurst \& Harrington, 2016). Research also shows, however, that in some situations dying people can experience a sense of social obligation to present an outward appearance of hope, as a means of protecting their loved ones (Sachs, Kolva, Pessin, Rosenfeld, \& Breitbart, 2013). Similarly, recent evidence suggests that some caregivers avoid preparatory tasks related to dying based on fears that engaging in such actions may compromise hope and hasten death (Breen et al., 2018). Our findings add to this picture by highlighting that missed opportunities to address important end-of-life matters can be lost in circumstances where emphasis on hope necessitates the backgrounding of dying.

When considering the clinical implications of our findings it is important to first note that we do not intend to imply here that disclosure and awareness of dying are problematic per se. The importance and value that dying people and their caregivers tend to place on full and honest communication regarding dying is well established (Caswell, Pollock, Harwood, \& Porock, 2015; Hancock et al., 2007). Our findings do suggest, however, that earlier recognition of the dying status can also bring with it hidden complications for dying people that warrant consideration. For health professionals, recognising the extent to which dying people struggle with the ambiguity of the dying trajectory and understanding the steps they take to manage this ambiguity is important for the provision of quality care. Achieving complete accuracy in prognostication will never be possible. Furthermore, recent research evidence suggests that most doctors already acknowledge the limits relating to prognostic estimations with their patients (Henselmans, Smets, Han, de Haes, \& van Laarhoven, 2017). 
Regardless, it is in the management of the challenges and opportunities associated with the twin realities of living while dying and dying while living that dying people and those close to them might need understanding and support (Clemmer, Ward-Griffin, \& Forbes, 2008). Better understanding the way in which dying people attempt to manage the elongated drama of contemporary dying is thus critical to the design and delivery of more sensitive, flexible and compassionate care.

\section{Limitations}

To be eligible for participation in this study, participants needed to be both aware of their dying diagnosis and well enough to participate in an interview. These requirements may have affected the nature of our findings in that data was not gathered from individuals with rapidly progressing disease or from people who had not yet been made aware of their dying status. With this in mind, it is likely that the ideas discussed in this paper will not be applicable to all forms of dying and should, therefore, be interpreted with caution. The inclusion and exclusion criteria also meant that participants who considered themselves as being very close to death were not interviewed. The way in which the dying role unfolds in the final scenes of life and the way in which role enactment in the preceding scenes may affect this process were beyond the scope of this study. Although it would be valuable to undertake further research into experiences during this phase of dying, doing so would be ethically challenging (Aoun, Slatyer, Deas, \& Nekolaichuk, 2017; Bloomer, Hutchinson, Brooks, \& Botti, 2018). Interviewing family and/or caregivers after the death of their loved one may lead to some valuable insights, however, researchers would need to remain mindful of the potential for the perspectives of dying people to be lost through such an approach.

\section{Conclusion}

In this paper, we have examined the transitions between living and dying roles at endof-life from the viewpoints of dying people and their caregivers and/or family members. We 
have identified that improvements in diagnosis of dying, coupled with uncertainty regarding prognostication can result in an elongated and ambiguous dying trajectory. We have suggested that dying people respond to this by periodically foregrounding and backgrounding living and dying selfhoods, living contingently, and reframing dying roles with a focus on living. All of these approaches serve an important function in promoting and maintaining hope for dying people and their loved ones. However, sometimes they can also result in missed opportunities for addressing end-of-life matters that dying role relations would otherwise afford. 


\section{References}

Aoun, S., Slatyer, S., Deas, K., \& Nekolaichuk, C. (2017). Family caregiver participation in palliative care research: Challenging the myth. Journal of Pain and Symptom Management, 53(5), 851-861. doi:10.1016/j.jpainsymman.2016.12.327

Aries, P. (1981). The hour of our death. (H. Weaver, Trans.). New York: Alfred A. Knopf.

Baldwin, P. K. (2017). Death cafés: Death doulas and family communication. Behavioral Sciences, 7(2), 1-8. doi:10.3390/bs7020026

Bloomer, M. J., Hutchinson, A. M., Brooks, L., \& Botti, M. (2018). Dying persons' perspectives on, or experiences of, participating in research: An integrative review. Palliative Medicine, 32(4), 851-860. doi:10.1177/0269216317744503

Breen, L. J., Aoun, S. M., O'Connor, M., Howting, D., \& Halkett, G. K. B. (2018). Family caregivers' preparations for death: A qualitative analysis. Journal of Pain and Symptom Management. doi:https://doi.org/10.1016/j.jpainsymman.2018.02.018

Broadhurst, K., \& Harrington, A. (2016). A mixed method thematic review: the importance of hope to the dying patient. Journal of Advanced Nursing, 72(1), 18-32. doi:10.1111/jan.12765

Bryant, A., \& Charmaz, K. (2010). The SAGE handbook of grounded theory (Pbk. ed.). Los Angeles: Sage.

Byrne, M. (2001). The concept of informed consent in qualitative research. AORN journal, 74(3), 401-403. doi:10.1016/S0001-2092(06)61798-5

Caswell, G., Pollock, K., Harwood, R., \& Porock, D. (2015). Communication between family carers and health professionals about end-of-life care for older people in the acute hospital setting: a qualitative study. BMC Palliative Care, 14(1), 35. doi:10.1186/s12904-015-0032-0

Charmaz, K. (2014). Constructing grounded theory (2nd ed.). London: Sage.

Clemmer, S. J., Ward-Griffin, C., \& Forbes, D. (2008). Family members providing homebased palliative care to older adults: the enactment of multiple roles. Canadian Journal on Aging, 27(3), 267-283.

Creswell, J. W. (2013). Qualitative inquiry and research design: choosing among five approaches (3rd ed.). Thousand Oaks, CA: Sage.

Dey, I. (2010). Grounding categories. In A. Bryant \& K. Charmaz (Eds.), The SAGE handbook of grounded theory (pp. 167-190). Los Angeles: Sage.

Doka, K. J. (2003). The death awareness movement. In C. D. Bryant (Ed.), Handbook of death \& dying (pp. 50-56). Thousand Oaks, CA: Sage.

Emanuel, L., Bennett, K., \& Richardson, V. E. (2007). The dying role. Journal of Palliative Medicine, 10(1), 159-168.

Field, D. (1996). Awareness and modern dying. Mortality, 1(3), 255-265. doi:10.1080/13576279609696247

Field, D., \& Copp, G. (1999). Communication and awareness about dying in the 1990s. Palliative Medicine, 13(6), 459-468. doi:10.1191/026921699668763479

Glaser, B. G., \& Holton, J. A. (2004). Remodeling grounded theory. Forum Qualitative Sozialforschung, 5(2).

Glaser, B. G., \& Strauss, A. L. (1965). Awareness of dying. Chicago.: Aldine Transaction.

Glaser, B. G., \& Strauss, A. L. (1967). The discovery of grounded theory: Strategies for qualitative research. New York: Aldine Pub. Co.

Goffman, E. (1959). The presentation of self in everyday life. New York: Penguin Books.

Hancock, K., Clayton, J. M., Parker, S. M., Walder, S., Butow, P. N., Carrick, S., . . .

Tattersall, M. H. N. (2007). Discrepant perceptions about end-of-life communication: 
A systematic review. Journal of Pain and Symptom Management, 34(2), 190-200. doi:https://doi.org/10.1016/j.jpainsymman.2006.11.009

Henselmans, I., Smets, E. M. A., Han, P. K. J., de Haes, H. C. J. C., \& van Laarhoven, H. W. M. (2017). How long do I have? Observational study on communication about life expectancy with advanced cancer patients. Patient education and counseling, 100(10), 1820-1827. doi:10.1016/j.pec.2017.05.012

Holton, J. A. (2010). The coding process and its challenges. In A. Bryant \& K. Charmaz (Eds.), The SAGE handbook of grounded theory (pp. 265-289). Los Angeles: Sage.

Howe, E. (2016). The "dying role": A new path, already well trodden. Psychiatry, 79(3), 208211. doi:10.1080/00332747.2016.1222159

Kellehear, A. (2007). A social history of dying. New York: Cambridge University Press.

Kellehear, A. (2009). The study of dying. From autonomy to transformation. Cambridge: Cambridge University Press.

Layder, D. (1993). New strategies in social research: An introduction and guide. Cambridge, U.K: Polity Press.

Lokker, M., Zuylen, L., Veerbeek, L., Rijt, C., \& Heide, A. (2012). Awareness of dying: It needs words. Supportive Care in Cancer, 20(6), 1227-1233. doi:10.1007/s00520-0111208-7

Miles, L., \& Corr, C. A. (2017). Death cafe: what is it and what we can learn from it. Omega - Journal of Death and Dying, 75(2), 151-165. doi:10.1177/0030222815612602

Morse, J. M. (2010). Sampling in grounded theory. In A. Bryant \& K. Charmaz (Eds.), The SAGE handbook of grounded theory (pp. 229-244). Los Angeles: Sage.

Noyes, R., Jr., \& Clancy, J. (1977). The dying role: Its relevance to improved patient care. Psychiatry, 40(1), 41-47.

Nyatanga, B. (2013). Dying matters awareness week: Refocusing on sensitivities of dying. British Journal of Community Nursing, 18(4), 202.

Parker-Oliver, D. (2000). The social construction of the "dying role" and the hospice drama. Omega - Journal of Death \& Dying, 40(4), 493-512.

Sachs, E., Kolva, E., Pessin, H., Rosenfeld, B., \& Breitbart, W. (2013). On sinking and swimming: The dialectic of hope, hopelessness, and acceptance in terminal cancer. American Journal of Hospice and Palliative Medicine, 30(2), 121-127. doi:10.1177/1049909112445371

Saldana, J. (2013). The coding manual for qualitative researchers (2nd ed.). London: Sage.

Seale, C., Addington-Hall, J., \& McCarthy, M. (1997). Awareness of dying: Prevalence, causes and consequences. Social Science \& Medicine, 45(3), 477-484. doi:10.1016/s0277-9536(96)00379-6

Snowden, M. (2015). Use of diaries in research. Nursing Standard, 29(44), 36-41. doi:10.7748/ns.29.44.36.e9251

Thomas, S. (2012). Narrative inquiry: Embracing the possibilities. Qualitative Research Journal, 12(2), 206-221. doi:10.1108/14439881211248356

Walter, J. A. (1994). The revival of death. New York: Routledge.

Walters, G. (2004). Is there such a thing as a good death? Palliative Medicine, 18(5), 404408. doi:http://dx.doi.org/10.1191/0269216304pm908oa 


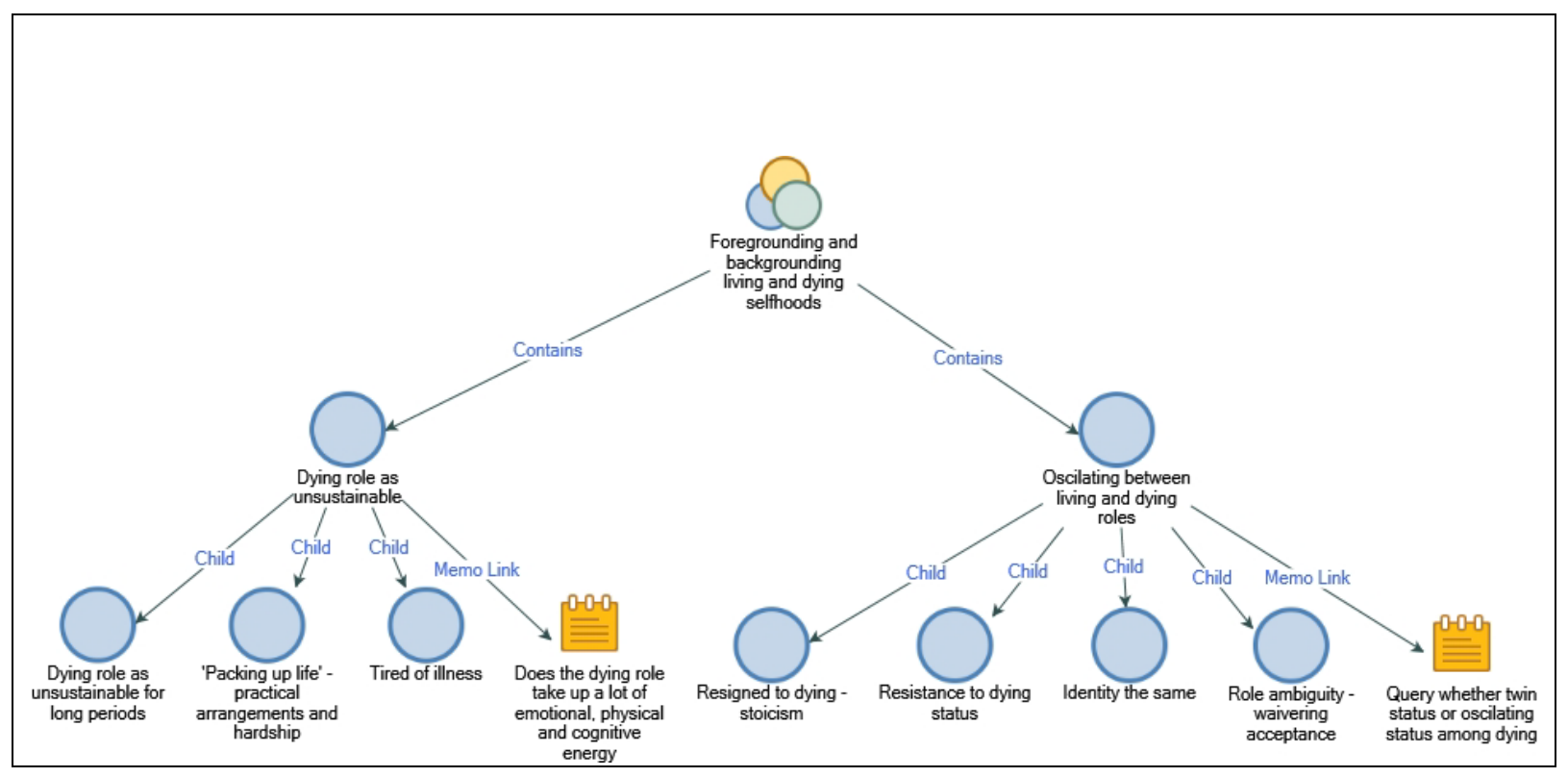

